\title{
Pena-Shokeir fenotipi: Bir olgu sunumu
}

\section{Pena-shokeir phenotype: A case report}

\section{Gülseren Erkoca Göktolga*, Hande Küçük Kurtulgan, Fatih Bolat, Gökay Göktolga, Şenol Çitli, Nejmiye Akkuş, İlhan Sezgin}

Tıbbi Genetik Anabilim Dalı (Dr. G. Erkoca Göktolga, Dr. H. Küçük Kurtulgan, Prof. Dr. İ. Sezgin, Dr. Ş. Çitli, Dr. N. Akkuş), Pediyatri Anabilim Dalı (Yrd. Doç. Dr. F. Bolat) Cumhuriyet Üniversitesi Tıp Fakültesi TR-58140 Sivas, Göz Hastalıkları Kliniği (Dr. G. Göktolga), Sivas Numune Hastanesi, TR-58040 Sivas

\section{Özet}

Pena-Shokeir fenotipi, multipl eklem kontraktürleri, yüz anomalileri ve pulmoner hipoplazi ile karakterize bir hastalıktır. Bu olguda mikrosefali, asimetrik yüz, mikrognati, kısa boyun, düşük retroverte kulak yapısı, kubbe damak, yüksek burun kökü, anteverte nostril, ellerde ulnar deviasyon, kamptodaktili, dirsekte fleksiyon kontraktürü, diz ve kalça eklemlerinde ankiloz, rocker bottom feet, club feet, vücut çizgilerinde silinme olan bir erkek hasta sunulmuştur.

Anahtar sözcükler: Pena-Shokeir, multipl eklem kontraktürü, fasial anomali, akciğer hipoplazisi

\begin{abstract}
Pena-Shokeir phenotype is characterized by multiple ankylosis, facial anomalies and, pulmonary hypoplasia In this case, a male patient with microcephaly, asymmetric face, micrognathia, short neck, low set and posteriorly angulated ears, high-arched palate, high nasal bridge, anteverte nostril, ulnar deviation of the hands, camptodactly, flexion contracture at elbow, ankylozis at hip and knee, rocker bottom feet, club feet, sparse absent dermal ridges is described.
\end{abstract}

Keywords: Pena-Shokeir, multiple joint contractures, facial anomalies, pulmonary hypoplasia

Geliş tarihi/Received: 25 Kasım 2011; Kabul tarihi/Accepted: 18 Ekim 2012

\section{*iletişim adresi:}

Dr. Gülseren Erkoca Göktolga, Tibbi Genetik Anabilim Dalı, Cumhuriyet Üniversitesi Tıp Fakültesi TR-58140 Sivas. E-posta: gulseren.goktolga@ gmail.com

\section{Giriş}

1974 yılında Pena ve Shokeir tarafından multipl eklem kontraktürleri, fasial anomaliler ve pulmoner hipoplaziyi içeren erken letal bir hastalık olan Pena-Shokeir fenotipi tanımlanmıştır [1]. Prenatal başlayan büyüme geriliği vardır, baş çevresi sıklıkla küçüktür. Hipertelorizm, telekantus, epikantal fold, küçük ve posterior rotasyonlu kulaklar, deprese burun yapısı, küçük ağız, yüksek damak, mikrognati, multipl ankiloz (dirsek, diz, kalça, ayak bileği), ellerde unlar deviasyon, rocker-bottom feet, talipes eqiunovarus, kamptodaktili, dermal çizgilerin azlığı veya yokluğu (sıklıkla ellerde ve parmaklarda flexiyon çizgilerinin yokluğu), pulmoner hipoplazi, kriptorşidizm, kısa boyun, polihidramniyos, küçük veya anormal plasenta, kısa umblikal kord sık görülen anomalilerdendir [2]. Yarık damak, kardiak defektler nadir görülen anomalilerdir. Otozomal resesif (OR) geçiş bildirilmektedir. Yayınlanmış vakaların yarısında OR geçiş tarif edilmekle birlikte X'e bağlı geçiş de bildirilmiştir [3, 4]. Son yıllarda yapılan çalışmalarda Pena-Shokeir fenotipinin tek bir etyolojiye bağlı olmadığı gösterilmiştir [5]. 


\section{Olgu sunumu}

Otuz bir yaşındaki sağlıklı anne ve babadan miadında doğmuş bir günlük erkek bebekti. Annenin üçüncü gebeliğiydi ve diğer iki kardeş sağlıklı ve erkekti. Fizik muayenesinde kilosu 2840 gr, boyu 46 cm'di. Mikrosefali, mikrognati, asimetrik yüz görünümü, kısa boyun, düşük ve retroverte kulak yapısı, kubbe damak, yüksek ve geniş burun kökü, anteverte nostril (Resim 1 ve 2), ellerde ulnar deviasyon ve kamptodaktili, el bileği ve dirsekte fleksiyon kontraktürü (Resim 3), rocker-bottom feet, club foot (Resim 4), diz ve kalça ekleminde ankiloz, vücut çizgilerinde silinme görülen bulgulardı (Resim 5).

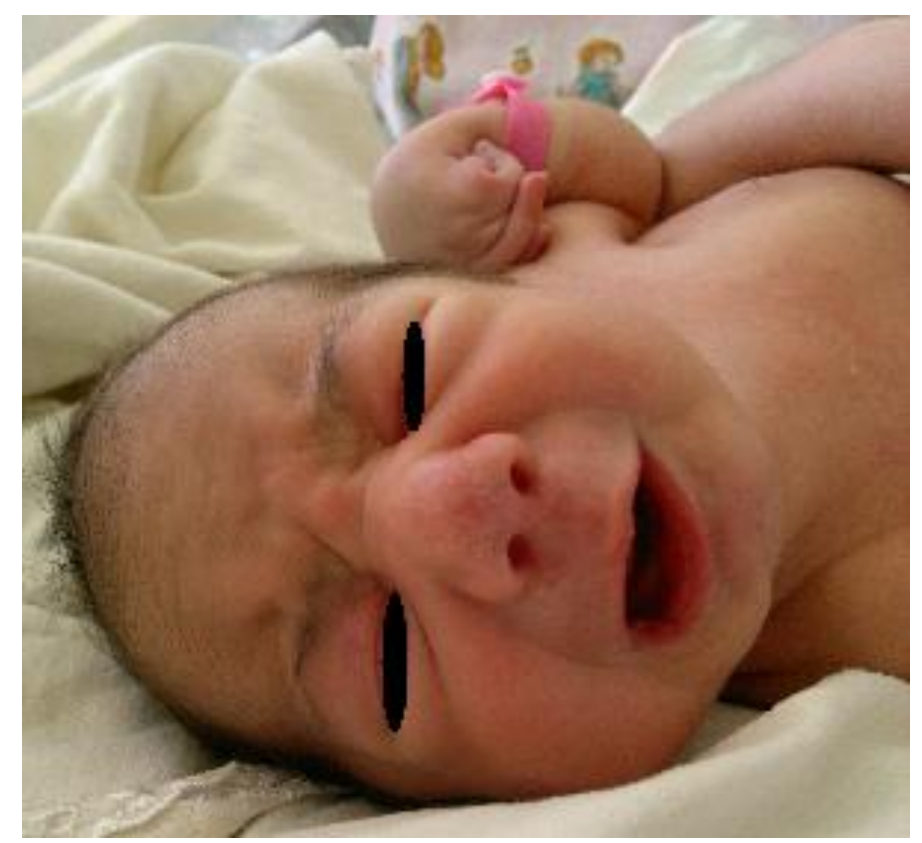

Resim 1. Mikrosefali, mikrognati, asimetrik, yüz, yüksek ve geniş burun kökü.

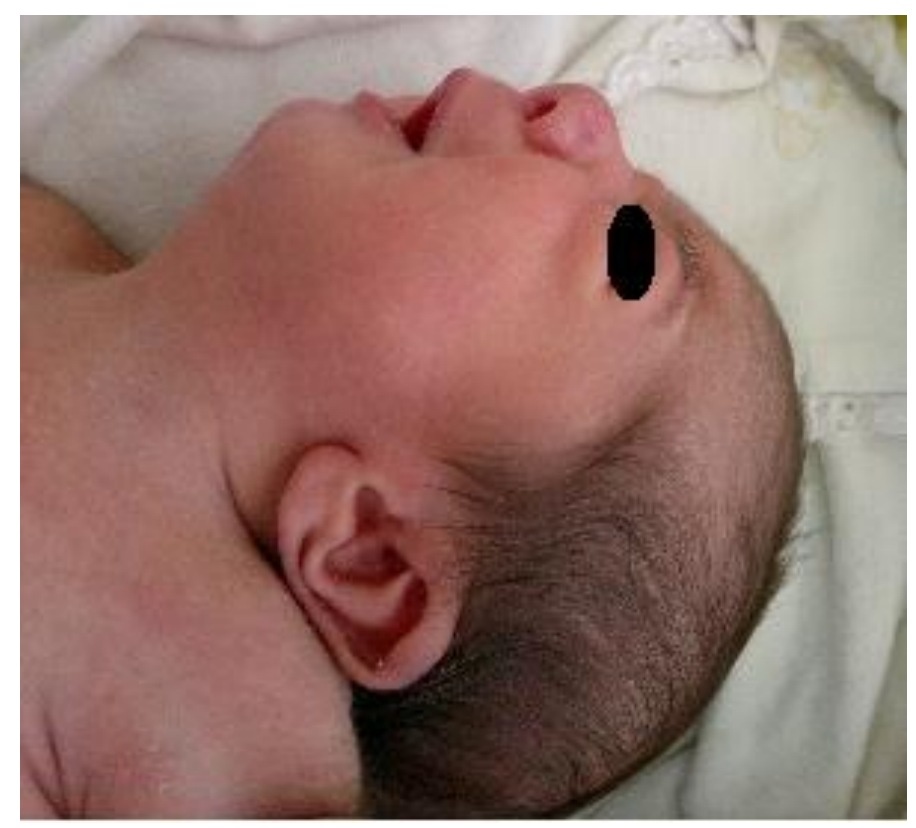

Resim 2. Kısa boyun, düşük ve retroverte kulak. 


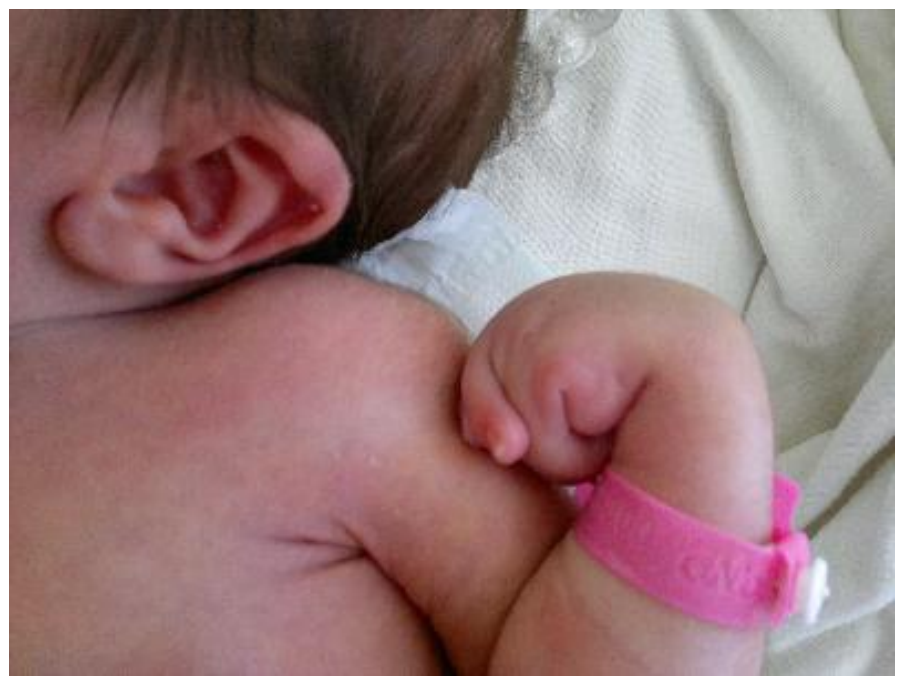

Resim3. El bileği ve dirsekte fleksiyon kontraktürü, kamptodaktili

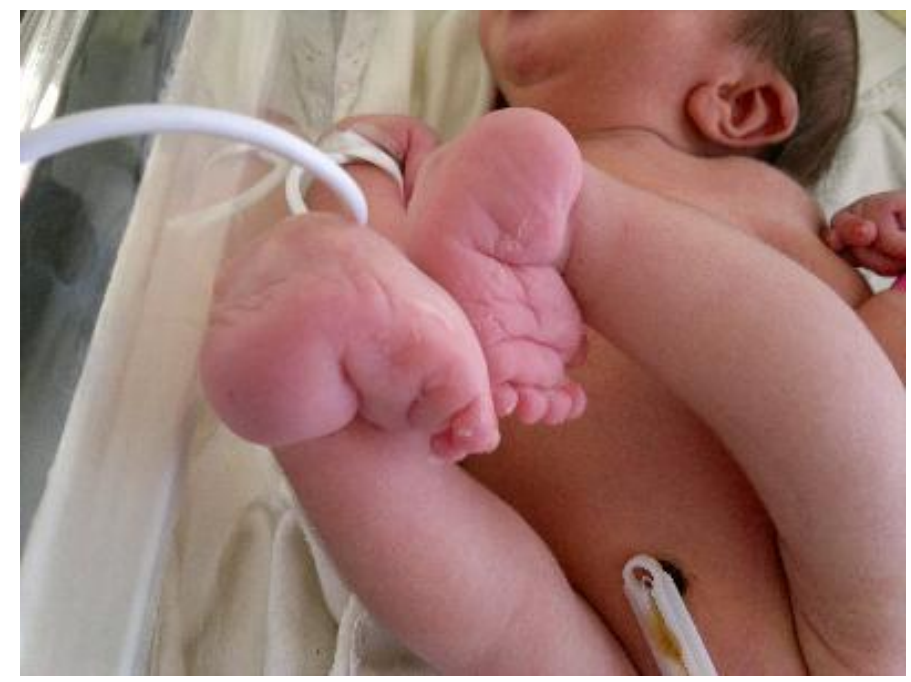

Resim 4. Rocker-bottom feet, club foot.

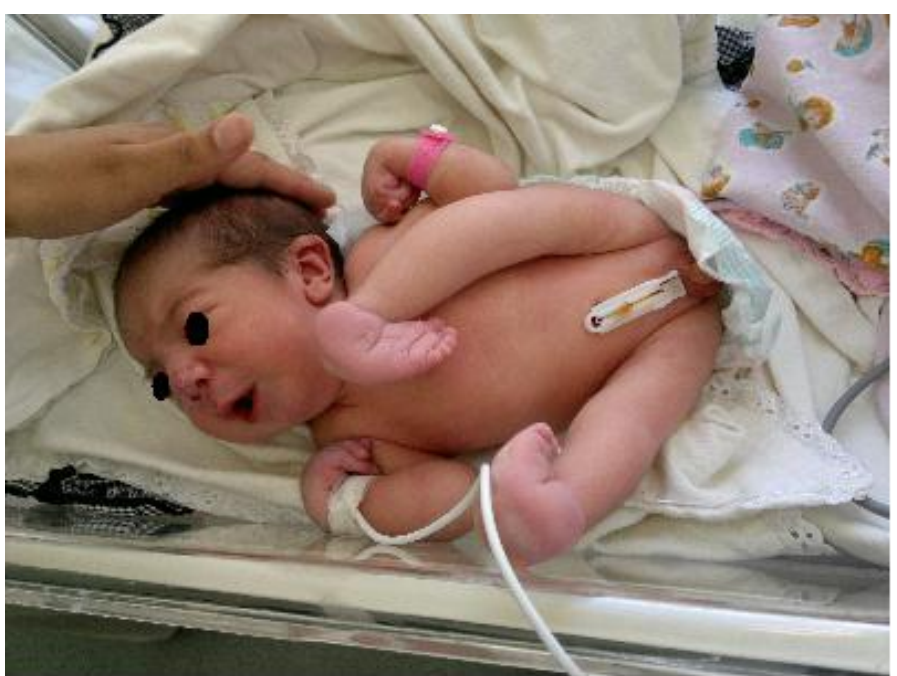

Resim 5. Kalça ve diz ekleminde ankiloz, vücut çizgilerinde silinme. 
Hemogram ve biyokimyasal incelemeleri normaldi. Batın ultrasonografisi (USG) , tranfontanel USG ve beyin manyetik rezonans görüntülemesi normaldi. Hastadan kromozom analizi çalışıldı, 46XY normal kromozom kurulumu olarak değerlendirildi. Anne ve baba arasında akrabalık yoktu. Ailede diğer çocuklar sağlıklıydı ve akrabalarda benzer özellikler yoktu.

\section{Tartışma}

Pena-Shokeir fenotipi ilk olarak Pena ve Shokeir tarafindan 1974'te artrogripozis, kamptodaktili, fasiyal anomaliler ve pulmoner hipoplazi ile karakterize letal otozomal resesif bir sendrom olarak tanımlanmıştır [1]. Nadir görülen bu sendromun insidansı yaklaşık olarak 1/12000 doğumdur. Prognozu kötüdür, etkilenmiş bebeklerin \%30'u ölü doğar. Canlı doğanların çoğu erken neonatal dönemde pulmoner hipoplaziye bağlı komplikasyonlar sebebiyle ölür [6]. Olguların yaklaşık yarısında OR(otozomal resesif) geçiş bildirilmiştir, ancak bu sendromun birden çok etyolojik nedene bağli olduğu ve bundan dolayı böyle ailelere verilecek genetik danışmanlığın çok güç olduğu bildirilmiştir. Sporadik vakalarda tekrarlama riski \%0-25 civarında olduğu tahmin edilmektedir [1]. Hipertelorizm, telekantus, epikantal fold, küçük ve posterior rotasyonlu kulaklar, deprese burun yapısı, küçük ağız, yüksek damak, mikrognati, multipl ankiloz (dirsek, diz, kalça, ayak bileği), ellerde ulnar deviasyon, rocker-bottom feet, talipes eqiunovarus, kamptodaktili, dermal çizgilerin azlığı ve yokluğu (sıklıkla ellerde ve parmaklarda fleksiyon çizgilerinin yokluğu), pulmoner hipoplazi, kriptorşidizm, kısa boyun, polihidramniyos, küçük veya anormal plasenta, kısa umblikal kord sık görülen anomalilerdendir [2]. Solunum ve ekstremite fonksiyonlarının normal gelişimi için uterus içerisinde fetal hareketin sürekliliği gerekmektedir. Ĕger hareketler durursa eklem sertleşir ve kas kitlesi azalır. Polihidramniyoz ve pulmoner hipoplazi normal solunumun yokluğu ve yutkunmanın azalmasıyla ilişkilidir [6]. Pena-Shokeir sendromunda omurga kasları, üst ve alt ekstremiteler etkilenir ve deformiteler bilateral ve simetriktir. Bu vakada da üst ve alt ekstremiteler simetrik ve bilateral olarak etkilenmişti. Ancak vakada pulmoner hipoplazi yoktu [7]. Pena-Shokeir fenotipik olarak trizomi 18'e benzediği için ayırıcı tanısının yapılması gerekir. Trizomi 18'de hipertonisite, iskelet kaslarında hipoplazi, inguinal-umbilikal herni, ventriküler septal defekt, atrial septal defekt, patent duktus arteriyozus gibi kalp anomalileri sik rastlanan bulgular arasındadır [2, 8]. Bu bulgular vakada bulunmamaktaydı. Kamptodaktili, rocker bottom feet, club foot trizomi 18 'de de görülen bulgulardı. Kromozom analiyle trizomi 18 ekarte edildi.

Sonuç olarak belirgin eklem kontraktürleri, fasiyal anomalileleri olan hasta benzer sendromlar ekarte edilerek sunulmuştur.

\section{Kaynaklar}

1. Pena SD, Shokeir MH. Syndrome of camptodactyly, multiple ankyloses, facial anomalies, and pulmonary hypoplasia: a lethal condition. J Pediatr 1974; 85: 373.

2. Jones KL. SMITH'S Recognizable Patterns of Human Malformation. 6th ed. Philadelphia: Elsevier, 2006; pp: 188.

3. Gyr T, Katz M, Altermatt HJ, Braga S, Duerig P, Koenig C, Schneider H. Lethal Pena-Shokeir 1 Syndrome in three male siblings. Arch Gynecol Obstet 1992; 251: 149; 54.

4. Enid Gilbert-Barness AO MD FRCPA FRCPath DSci(hc) MD(hc) (Editor), Raj P. Kapur MD PhD (Editor), Luc Laurier Oligny MSc MD (Editor), Joseph R. Siebert PHD (Editor)

5. Barness EG, Raj P. Kapur, Luc Laurier Oligny. Joseph R. Siebert (Eds). Potter's Pathology of the Fetus and Infant and Child. 2nd ed. Mosby, 1997; pp: 92-3.

6. Lavi E, Montone KT, Rorke LB, Kliman HJ. Fetal akinesia deformation sequence (Pena-Shokeir phenotype) associated with acquired intrauterine brain damage. Neurology 1991; 41: 1467-8.

7. Ajayi RA, Keen CE, Knott PD. Ultrasound diagnosis of the Pena Shokeir 
phenotype at 14 weeks of pregnancy. Prenat Diagn 1995; 15: 762-4.

8. Senocak EU, Oguz KK, Haliloglu G, Karcaaltincaba D, Akata D, Kandemir O. Prenatal diagnosis of Pena-Shokeir syndrome phenotype by ultrasonography and MR imaging. Pediatr Radiol 2009; 39: 377-80.

9. Gupta P, Sharma JB, Sharma R, Gadodia A, Kumar S, Roy KK. Antenatal ultrasound and MRI findings of Pena-Shokeir syndrome. Arch Gynecol Obstet 2011; 283: 27-9. 